\title{
AS CONTRADIÇÕES DO CORPO: RELATO DE EXPERIÊNCIA NA CLÍNICA HEMATOLÓGICA
}

\author{
Nayara Ruben Calaça Menezes \\ Gabriela Borges Carvalho \\ Sebastião Benicio da Costa Neto \\ Hospital das Clínicas da Universidade Federal de Goiás (HC-UFG/EBSERH)
}

\begin{abstract}
Resumo
O presente trabalho é um relato de experiência sob a ótica de duas residentes de psicologia inseridas no Programa de Residência Multiprofissional em Saúde do Hospital das Clínicas da Universidade Federal de Goiás (HC-UFG/EBSERH), que atuam no eixo Hematologia e Hemoterapia. Pretende-se, a partir do presente estudo descrever e discutir sobre a experiência e vivência em um atendimento com paciente diagnosticado com Anemia Falciforme à luz da teoria da psicossomática. Para tanto, foi realizado uma breve contextualização do Programa de Residência Multiprofissional em Saúde e sobre o quadro de Anemia Falciforme, a apresentação do caso e as percepções das autoras sobre a vivência do atendimento psicológico.
\end{abstract}

Palavras-chave: hematologia; psicossomática; anemia falciforme; doenças crônicas

\section{Abstract \\ The Contradictions of the Body: Experience Report in Haematological Clinic}

The present work is an experience report from the perspective of two psychology residents inserted in a Multiprofessional Health Residency Program in the Hospital das Clínicas of the Federal University of Goiás (HC-UFG/ EBSERH), which work in the hematology and hemotherapy area. The aim of this study is to describe and discuss the experience of a patient diagnosed with Sickle Cell Anemia in the light of psychosomatic theory. For that, was realized a brief contextualization of the Multiprofessional Health Residency Program and about the Sickle Cell Anemia, the presentation of the case and the perceptions of the authors about the experience of the psychological care.

Keywords: hematology; psychosomatic; sickle cell anemia; chronic diseases

O presente trabalho surge como fruto

I. Introdução de uma vivência ocorrida durante a Residência Multiprofissional em Saúde, que 
se constitui como uma modalidade de ensino de pós-graduação lato sensu destinado às profissões que se relacionam com a saúde, sob a forma de Curso de Especialização caracterizado por ensino em serviço, sob a orientação de profissionais de elevada qualificação ética e profissional. (Brasil, 2007). Criado a partir da promulgação da Lei $\mathrm{n}^{\circ} 11.129$ de 2005 e orientado pelos princípios e diretrizes do Sistema Único de Saúde (SUS), a partir das necessidades e realidades locais e regionais, a Residência Multiprofissional abrange diversas profissões da área da saúde, como: Biomedicina, Ciências Biológicas, Educação Física, Enfermagem, Farmácia, Fisioterapia, Fonoaudiologia, Medicina Veterinária, Nutrição, Odontologia, Psicologia, Serviço Social e Terapia Ocupacional.

Nesse contexto, o profissional da Psicologia busca abordar as manifestações da subjetividade humana frente ao adoecimento, incluindo sonhos, conflitos, sentimentos, desejos, estilo de vida, dentre outros, buscando abordar as angústias expressas ou latentes identificadas nas falas dos pacientes hospitalizados (Simonetti, 2016).

O presente relato de experiência, tem como foco um paciente, internado na Clínica Médica da instituição, diagnosticado com
Anemia Falciforme, patologia descrita pela primeira vez pelo médico americano James B. Herrick, em 1910, que acredita-se ter origem na Ásia Menor e na África, sendo que durante o processo de colonização e escravização da população negra africana, a doença, devido a grande miscigenação entre os povo de todos os países, tenha se espalhado para todos os continentes, sendo hoje encontrada tanto em pessoas negras e pardas quanto em pessoas brancas. (Pereira e outros, 2008).

De acordo com o Ministério da Saúde, atualmente, a Anemia Falciforme, é considerada uma das alterações genéticas mais frequentes no Brasil e no mundo. Trata-se de uma doença hemolítica hereditária e crônica que acontece

[...] devido a troca de um aminoácido na cadeia beta da hemoglobina $\mathrm{S}$, ocasionando grandes alterações nas propriedades físico-químicas da molécula da hemoglobina quando desoxigenada. Tais alterações resultam na mudança de forma da hemácia para a de foice, sendo este um dos principais mecanismos fisiopatológicos da doença (Brasil, 2009, p.11).

Dessa forma, nas pessoas com Anemia Falciforme, as hemácias adquirem 
forma de foice e, devido a esse formato, não conseguem circular adequadamente, causando a obstrução do fluxo sanguíneo capilar e também sua prematura destruição. Conclui-se então que os sintomas clínicos observados neste agravo são decorrentes da alteração do formato normal das hemácias. (Brasil, 2009).

Segundo Santos e Miyazaki (1999), as estimativas com base na prevalência, permitem assegurar a existência de mais de 2 milhões de portadores do gene da HBS no Brasil, mais de 8000 afetados com a forma homozigótica (HBSS). Sendo que, de acordo com o Programa Nacional de Triagem Neonatal (PNTN), no Brasil, nascem a cada ano cerca de 3.500 crianças portadoras de AF; dessas, 20\% não atingem os 5 anos de idade por complicações da doença (Brasil, 2012), desencadeando assim, um problema de saúde pública.

Os primeiros sinais e sintomas do agravo manifestam-se ainda nos primeiros meses de vida da criança, sendo alguns dos sintomas fatores determinantes da qualidade de vida desses pacientes, dentre eles podemos destacar as crises álgicas ósteoarticulares, que podem ser intensas e progressivas resultando da obstrução de microcirculações, gerando dores no paciente que podem ser de grau leve, moderado e intenso (Carvalho, 2010).

Segundo Silva e Marquez (2007), a dor se apresenta como a maior manifestação clínica da doença, outro sintoma clínico importante refere-se às complicações cerebrovasculares que envolvem infarto cerebral, hemorragia cerebral e alterações cognitivas e comportamentais que podem ocorrer em aproximadamente $25 \%$ dos pacientes. O quadro clínico de Anemia Falciforme ainda é marcado pela presença de palidez, cansaço fácil, icterícia, úlceras nas pernas e maior tendência a infecções. (Dias, 2013)

Por ser uma doença genética, ela requer, além do diagnóstico precoce, o autocuidado e a assistência multiprofissional, de modo que o indivíduo acometido e a família sejam preparados para lidar com toda a sintomatologia dessa condição (Dias, 2013). Embora tratável, a doença falciforme ainda é incurável, ou seja, o tratamento precoce comprovadamente aumenta a sobrevivência e melhora a qualidade de vida, mas não possibilita a sua cura clínica.

O diagnóstico precoce da doença falciforme só é possível pela realização do exame de triagem neonatal, conhecido como teste do pezinho. Este exame laboratorial, 
feito a partir do sangue coletado do recémnascido entre o terceiro e o quinto dia de vida, permite identificar se hemoglobinas presentes no sangue se apresentam com o formato normal ou em foice.

O acompanhamento da Anemia Falciforme deve proporcionar a promoção do conhecimento da sobre a doença, a facilitação do acesso aos serviços de diagnóstico e tratamento, bem como as ações educativas dirigidas à população, uma vez que os quadros clínicos específicos da doença muitas vezes podem ser controlados e amenizados pelo próprio paciente que, orientado sobre sua doença, desempenhará um papel importante no controle das crises (Santos \& Miyazaki, 1999).

Sabe-se que existe um número substancial de problemas secundários associados à patologia crônica, como dificuldade no relacionamento familiar, na interação com colegas, no rendimento acadêmico e no desenvolvimento de uma autoimagem positiva. Uma doença crônica é fonte de estressores permanente na vida do paciente e de sua família. (Santos \& Miyazaki, 1999).

Pensando na doença crônica e nas crises álgicas recorrentes em pacientes com Anemia Falciforme, deve-se considerar os fatores emocionais envolvidos em suas queixas, sabendo-se que o estado afetivo é um elemento importante da vivência dolorosa (Rocha, 2016). Essa via de expressão de conteúdos psíquicos e inconscientes através de sintomas no corpo, tem sido estudada e pesquisada por diferentes saberes, surgindo então o termo psicossomática, em que o estudo da relação mente-corpo passou a ser olhada de uma forma mais rica e completa (Santos Filho, 2010).

Dessa forma, surge a Medicina Psicossomática, um campo recente na saúde que trabalha em diferentes perspectivas, a saber: a doença em sua dimensão psicológica; a relação médico-paciente e seus desdobramentos; a ação terapêutica voltada para o sujeito e não para sua doença, com uma visão biopsicossocial (Santos Filho, 2010).

Sendo assim, a importância do presente estudo consiste na possibilidade de contribuir para a visualização e compreensão de quadros psicossomáticos derivados de doenças crônicas como a Anemia Falciforme, a partir da ilustração da manifestação de quadros psicossomáticos no contexto hospitalar.

\section{O Corpo que Dói: Descriçãa do Caso Clínico}


$\mathrm{O}$ caso apresentado refere-se ao paciente Aquiles (nome fictício, que significa sofrimento e dor, mas também "espírito de vida"), sexo masculino, 25 anos, solteiro, sem filhos, pardo, proveniente de uma cidade do interior da Bahia. O paciente iniciou o tratamento e acompanhamento com o Serviço de Hematologia do Hospital das Clínicas da Universidade Federal de Goiás (HC-UFG/EBSERH), após mudar, com dois irmãos, para Goiânia, em busca de uma melhor qualidade de vida.

Após a mudança de cidade, um dos irmãos do paciente sentiu fortes dores e foi encaminhado para uma unidade de saúde onde recebeu o diagnóstico tardio de Anemia Falciforme e, devido ao longo tempo sem tratamento seu quadro acabou evoluindo para óbito. A partir dessa perda, o hospital acionou os familiares para que realizassem exames visando identificar se mais algum dos familiares possuía Anemia Falciforme, realizando o diagnóstico de Aquiles nesse momento.

Durante as internações acompanhadas, Aquiles apresentava extrema resistência em aderir ao tratamento e acompanhamento médico e psicológico, sendo estigmatizado pela equipe como um paciente difícil, uma vez que demandava a atenção da equipe assistencial a todo momento.

\section{Resultados e Discussões}

No caso retratado identificamos uma correlação expressa entre o aumento da frequência e intensidade das crises álgicas do paciente em momentos onde foi vivenciado algum conflito ou perda, o que possibilitou a análise de um quadro de dor psicossomática. Esse quadro se mostrou recorrente durante o período em que foi acompanhado pelas residentes de psicologia durante os períodos de intenção.

No primeiro atendimento realizado foi relatado que na noite anterior à hospitalização, ele e a mãe tiveram um grave desentendimento e que pela manhã o paciente já procurou a unidade de saúde devido às dores que começaram ainda durante a noite. Em um segundo atendimento, realizado alguns meses depois, foi relatado que o paciente retornou à unidade de saúde, novamente devido às crises álgicas, que tiveram início após o paciente ser demitido do emprego. Algumas semanas depois dessa segunda internação, o paciente retorna ao hospital com fortes crises álgicas e relata que um tio, muito próximo dele, foi a óbito. 
Levando em consideração os fatores emocionais e afetivos experienciados pelo paciente, quando avaliamos sua vivência dolorosa, é importante ressaltar, que pacientes com alterações psíquicas, que apresentam sintomas depressivos e quadros de ansiedade são os que mais se queixam de dor. Quadros de dor aguda geralmente estão associados com ansiedade, e além disso, pacientes que vivem com uma dor crônica, apresentam sintomas depressivos, pois a experiência de incapacidade e limitações que a doença gera desperta sentimentos de desânimo e tristeza diante dessa realidade incurável (Rocha, 2016).

$\mathrm{O}$ uso prolongado de medicações também pode influenciar nos quadros de humor, como por exemplo, surgimento de uma depressão secundária, e deve ser considerado nesses casos. Com isso, dor e angústia aparecem frequentemente no discurso desses pacientes, que releva a ligação da experiência dolorosa com os quadros afetivos.

Durante o período de internação, Aquiles demandava muita atenção e cuidado da equipe assistencial. Queixava-se de dor continuamente mesmo após ser medicado, e desafiava a equipe para que controlassem sua crise álgica de maneira mais efetiva. Passado algum tempo, era perceptível o incômodo da equipe com as demandas e queixas frequentes do paciente, e uma consequente desvalorização das suas queixas. Nesse momento, o paciente foi taxado pela equipe como "dependente de morfina" e suas queixas passaram a ser desacreditadas e desvalorizadas, pois passaram a acreditar que o paciente retornava à instituição apenas para ter acesso ao medicamento.

Freud (1914/2010) formula que aqueles que sofrem de alguma dor orgânica, perdem o interesse pelas coisas do mundo externo e o investimento libidinal volta-se para Eu. Diante disso, durante uma internação tivemos a informação que o paciente havia saído de casa após um conflito familiar e que se encontrava em situação de rua, com vínculos interrompidos e uma rede de apoio deficitária. Nessa circunstância o hospital se colocou como um local de referência para o paciente por assegurar necessidades básicas como alimentação e segurança, o que pode ter levado ao aparecimento de novas e sucessivas crises álgicas e internações.

É importante ressaltar que a relação entre os fatores emocionais e o aparecimento das crises álgicas não aparecia de maneira consciente no discurso do paciente e que o mesmo apresentava extrema resistência com 
o atendimento psicológico e com as intervenções propostas. Durante todas as internações tentamos abordar e elucidar essa correlação com o paciente, de forma que ele pudesse expressar essa dor de outra forma, que não no lugar de "doente" como foi nomeado pela instituição, visando favorecer a elaboração desse mecanismo de formação de sintomas psicossomáticos.

Desta forma, pode-se dizer que a dor orgânica corresponde a "dor da alma" que é manifestada no corpo como um pedido de socorro. Aquiles, ao vivenciar conflitos emocionais, manifestava através das crises álgicas um pedido de ajuda, e assim, o corpo dizia o que o paciente tinha dificuldades de manifestar em palavras. Conclui-se que a doença e a dor orgânica surgem então como uma metáfora, que marca o corpo do sujeito e a imagem inconsciente deste enquanto lugar de expressão dos conflitos pulsionais e afetivos, sendo preciso dar espaço a escuta dos ruídos e contradições desses corpos enfermos que pedem por socorro, como muito bem expressado na poesia de Carlos Drummond de Andrade, As contradições do corpo, de 1984.
Meu corpo não é meu corpo,
é ilusão de outro ser.
Sabe a arte de esconder-me
e é de tal modo sagaz.
que a mim de mim ele oculta.
Meu corpo, não meu agente, meu envelope selado, meu revólver de assustar, tornou-se meu carcereiro, me sabe mais que me sei.
[...]
Meu corpo inventou a dor
a fim de torná-la interna.
Integrante do meu Id,
ofuscadora da luz
que aí tentava espalhar-se.

\section{Referências}

Andrade. C. D. de. (1987/2015). As contradições do corpo. In Andrade, C. D. de. (1902/1987) Corpo (p.11-12). São Paulo: Companhia das Letras, 2010.

Brasil. Agência Nacional de Vigilância Sanitária. (2001). Manual de diagnóstico e tratamento de doenças falciformes. Recuperado de http://bvsms.saude.gov.br/bvs/publicacoes/anvisa/diagnostico.pdf 


\section{NAYARA RUBEN CALAÇA MENEZES, GABRIELA BORGES CARVALHO, SEBASTIÃO BENICIO DA COSTA NETO}

Brasil. Ministério da Educação, Ministério da Saúde. Portaria Interministerial no 45, de 12 de janeiro de 2007. Dispõe sobre a Residência Multiprofissional em Saúde e a Residência em Área Profissional da Saúde e institui a Comissão Nacional de Residência Multiprofissional em Saúde.

Brasil. Ministério da Saúde, Secretaria de Atenção à Saúde, Departamento de Atenção Especializada. (2009). Manual de eventos agudos em doença falciforme. Recuperado de http://bvsms.saude.gov.br/bvs/publicacoes/manual_eventos_agudos_doenca_falciforme.pdf

Brasil. Ministério da Saúde, Secretaria de Atenção à Saúde, Departamento de Atenção Especializada. (2012). Doença falciforme: Condutas básicas para tratamento. Recuperado de http://bvsms.saude.gov.br/bvs/publicacoes/doenca_falciforme_condutas_basicas.pdf

Carvalho, A. L. de O. (2010). Qualidade de vida em mulheres negras com anemia falciforme: Implicações de gênero (Dissertação de Mestrado). Recuperado de https://repositorio.ufba.br/ri/handle/ri/9314

Dias, T. L. e outros (2013, Dez). A dor no cotidiano de cuidadores e crianças com anemia falciforme. Psicologia USP, 24(3), 391-411. https://dx.doi.org/10.1590/S010365642013000300003

Freud, S. (2010). Introdução ao narcisismo. In: Freud, S. (1914-1916). Obras completas. Introdução ao narcisismo: ensaios de metapsicologia e outros textos (p.14-50). São Paulo: Companhia das Letras (Original publicado em 1914).

Pereira, S. A. A. e outros (2008, Out) Doença falciforme e qualidade de vida: Um estudo da percepção subjetiva dos pacientes da Fundação Hemominas, Minas Gerais, Brasil. Revista Brasileira de Hematologia e Hemoterapia, 30(5), 411-416. https://dx.doi.org/10.1590/S1516-84842008000500015

Rocha, R. L. da. (2016). Aspectos psicológicos em pacientes com dor crônica. In AngeramiCamon, V. A. (Org.). Psicossomática e psicologia da dor (2a ed., pp. 317-334). São Paulo: Pioneira Thomson Learning.

Santos Filho, O. C. (1993). Histeria, hipocondria e fenômeno psicossomático (pp. 108-112). In Mello Filho, J. (Org.). Psicossomática hoje. Porto Alegre: Artes Médicas.

Santos, A. R. R. dos \& Miyazaki, M. C. de O. (1999). Grupo de sala de espera em ambulatório de doença falciforme. Revista Brasileira de Terapia Comportamental e Cognitiva, 1(1), 41-48. Recuperado de http://pepsic.bvsalud.org/scielo.php?script=sci_arttext\&pid=S1517$55451999000100005 \& \operatorname{lng}=\mathrm{pt} \& \operatorname{lng}=\mathrm{pt}$

Simonetti, A. (2016). Manual de psicologia hospitalar: O mapa da doença. São Paulo: Casa do Psicólogo. 


\section{Os autores:}

Nayara Ruben Calaça Menezes tem graduação em Psicologia pela Universidade Federal de Goiás, Brasil (2016). Residência Multiprofissional em Saúde do Hospital das Clínicas da Universidade Federal de Goiás, e-mail: nayararuben@hotmail.com

Gabriela Borges Carvalho tem graduação em Psicologia pela Universidade Federal de Goiás, Brasil(2016), e-mail: gabrielaborgesc@hotmail.com

Sebastião Benicio da Costa Neto é Professor Adjunto II, orientador de mestrado e doutorado no Programa de PósGraduação em Psicologia, da Pontifícia Universidade Católica de Goiás (PUC Goiás). Possui graduação, Licenciatura e Bacharelado em Psicologia pela PUC Goiás - antes Universidade Católica de Goiás (1988), especialização em psicologia hospitalar (CEPAN/Goiânia, 1988), mestrado em Psicologia pela Universidade de Brasília (1994), doutorado em Psicologia pela Universidade de Brasília (2002 - Estágio doutoral no Hospital Universitário Gregório Marañon/Unidade Oncológica Príncipe de Astúrias - MADRID) e pós-doutorado em psicologia pela Universidade Federal do Rio Grande do Sul (2006). Atualmente é psicólogo hospitalar da Universidade Federal de Goiás, e-mail: sebastiaobenicio@gmail.com

Recebido em: 21/11/2018

Aprovado em: 29/12/2018 